\title{
Evolution of Microstructure and Texture During Warm Rolling of a Duplex Steel
}

\begin{abstract}
PINAKI PRASAD BHATTACHARJEE, M. ZAID, G.D. SATHIARAJ, and B. BHADAK
The effect of warm rolling on the evolution of microstructure and texture in a duplex stainless steel (DSS) was investigated. For this purpose, a DSS steel was warm rolled up to $90 \mathrm{pct}$ reduction in thickness at $498 \mathrm{~K}, 698 \mathrm{~K}$, and $898 \mathrm{~K}\left(225^{\circ} \mathrm{C}, 425^{\circ} \mathrm{C}\right.$, and $\left.625^{\circ} \mathrm{C}\right)$. The microstructure with an alternate arrangement of deformed ferrite and austenite bands was observed after warm rolling; however, the microstructure after 90 pct warm rolling at $498 \mathrm{~K}$ and $898 \mathrm{~K}$ $\left(225^{\circ} \mathrm{C}\right.$ and $\left.625^{\circ} \mathrm{C}\right)$ was more lamellar and uniform as compared to the rather fragmented and inhomogeneous structure observed after 90 pct warm rolling at $698 \mathrm{~K}\left(425^{\circ} \mathrm{C}\right)$. The texture of ferrite in warm-rolled DSS was characterized by the presence of the RD $(\langle 011\rangle / / \mathrm{RD})$ and ND $(\langle 111\rangle / / \mathrm{ND})$ fibers. However, the texture of ferrite in DSS warm rolled at $698 \mathrm{~K}\left(425^{\circ} \mathrm{C}\right)$ was distinctly different having much higher fraction of the RD-fiber components than that of the ND-fiber components. The texture and microstructural differences in ferrite in DSS warm rolled at different temperatures could be explained by the interaction of carbon atoms with dislocations. In contrast, the austenite in DSS warm rolled at different temperatures consistently showed pure metal- or copper-type deformation texture which was attributed to the increase in stacking fault energy at the warm-rolling temperatures. It was concluded that the evolution of microstructure and texture of the two constituent phases in DSS was greatly affected by the temperature of warm rolling, but not significantly by the presence of the other phase.
\end{abstract}

DOI: $10.1007 / \mathrm{s} 11661-013-2139-3$

(C) The Minerals, Metals \& Materials Society and ASM International 2013

\section{INTRODUCTION}

DUPLEX stainless steels (DSS) having a two-phase microstructure consisting of ferrite and austenite are widely used in corrosive environments such as chemical plants due to their excellent corrosion resistance and strength. However, to enhance the usage of DSS in a wide range of structural applications, proper understanding of the deformation and recrystallization behavior is required particularly in view of the additional complexity arising from the presence of the second phase in the microstructure. Surprisingly, the development of microstructure and texture during deformation and recrystallization in DSS has been studied to a much lesser extent as compared to single-phase austenitic or ferritic steels. Even then, most of the available prior studies on deformation behavior of DSS steels have focussed on the microstructure and texture evolution during cold deformation and subsequent annealing. ${ }^{[1-6]}$ It has been reported that ferrite and austenite in DSS deform independent of each other, leading to a deformation texture similar to the respective single-phase materials. ${ }^{[2]}$ However, few recent investigations have

PINAKI PRASAD BHATTACHARJEE, Assistant Professor, M. ZAID, and G.D. SATHIARAJ, Research Scholars, and B. BHADAK, M.Tech. Student, are with the Department of Materials Science and Engineering, Indian Institute of Technology Hyderabad, Ordnance Factory Estate, Yeddumailaram 502205, AP, India. Contact e-mail: pinakib@iith.ac.in

Manuscript submitted July 8, 2013.

Article published online December 18, 2013 shown that the development of the characteristic bandlike morphology having an alternate arrangement of bands of ferrite and austenite can influence the development of texture of the two constituent phases in DSS, particularly in the heavy strain regime. ${ }^{[7-9]}$ The situation may be further complicated by the fact that the starting microstructure and texture prior to cold rolling can significantly affect the subsequent development of microstructure and texture during cold rolling. ${ }^{[10-12]}$

In the present work, the evolution of microstructure and texture during heavy warm rolling of DSS in a wide temperature range is studied. It may be pointed out that the effect of warm rolling on microstructure and texture formation has been energetically studied in single-phase materials. ${ }^{[13-15]}$ However, there are hardly any studies being reported on DSS. From a commercial viewpoint, warm rolling is considered particularly beneficial in realizing new products and reduction in the production cost of hot-rolled strips. Effect of warm rolling is considered interesting particularly due to the fact that ferrite and austenite may show different softening behaviors. It is reported that single-phase ferrite shows recovery (or dynamic recovery)-type behavior, while single-phase austenite is a predominantly recrystallization-type material. ${ }^{[16,17]}$ These differences in the behavior of the two phases can also affect the evolution of microstructure and texture of DSS during warm rolling and subsequent recrystallization, but need to be studied in depth. Thus, the objective of the present investigation was to clarify the effect of warm rolling on the microstructure and texture evolution in DSS. 


\section{EXPERIMENTAL}

\section{A. Processing}

The starting material for this work was an as-cast DSS ingot having the shape of a tapered cylinder with top diameter $72 \mathrm{~mm}$, bottom diameter $62 \mathrm{~mm}$, and height $290 \mathrm{~mm}$. The chemical composition of the DSS alloy is shown in Table I. This was progressively hot forged or cogged at $1473 \mathrm{~K} \quad\left(1200{ }^{\circ} \mathrm{C}\right)$ to dimensions of $60 \mathrm{~mm}$ (thickness) $\times 55 \mathrm{~mm}$ (width) $\times 300 \mathrm{~mm}$ (length) . The hot-forged slab was subsequently hot rolled at $1398 \mathrm{~K}\left(1125^{\circ} \mathrm{C}\right)$ to $\sim 82.5 \mathrm{pct}$ reduction in thickness to a final thickness of $10.5 \mathrm{~mm}$ in 7 passes. Rectangular samples $300 \mathrm{~mm}$ (width) $\times 80 \mathrm{~mm}$ (length) were cut from the hot-rolled material and annealed at $1448 \mathrm{~K}\left(1175^{\circ} \mathrm{C}\right)$ for 2 hours in a tubular furnace in flowing argon atmosphere in order to achieve nearly equal volume fraction of the austenite and ferrite in the microstructure.

The annealed DSS samples were subsequently warm rolled up to $\sim 90$ pct reduction in thickness using multipass rolling at three different temperatures, $498 \mathrm{~K}$, $698 \mathrm{~K}$, and $898 \mathrm{~K}\left(225^{\circ} \mathrm{C}, 425^{\circ} \mathrm{C}\right.$, and $\left.625^{\circ} \mathrm{C}\right)$, using a laboratory scale rolling equipment (SPX Precision Equipment, USA) having rolls of $140 \mathrm{~mm}$ diameter. 10 passes were required to achieve the total deformation. Nearly 10 pct deformation was achieved in each pass up to 80 pct reduction (total 8 passes) and beyond that the deformation was achieved in two passes corresponding to $\sim 85$ and 90 pct reduction in thickness. A box-type furnace was used for the preheating purpose and a holding time of 15 minutes was used before each warmrolling pass to achieve homogeneity in temperature. The warm rolling was carried out along the original direction of hot rolling. The rolls were preheated to $523 \mathrm{~K}$ $\left(250{ }^{\circ} \mathrm{C}\right)$ in order to prevent the sudden quenching effect during warm rolling. The samples were immediately water quenched after every warm-rolling pass.

\section{B. Characterization}

The microstructure and microtexture of the deformed materials were characterized using an electron backscatter diffraction (EBSD) system (Oxford Instruments, UK) attached to a FEG-SEM (Make: Carl Zeiss, Germany, Model: SUPRA-40). The EBSD measurements were carried out using a constant accelerating voltage of $20 \mathrm{kV}$ and working distance close to $20 \mathrm{~mm}$ for most measurements. A fine scan step size of $50 \mathrm{~nm}$ was used for all measurements in the present work. Samples for EBSD were prepared by careful mechanical polishing followed by electropolishing at room temperature using an applied voltage of $27 \mathrm{~V}$ and holding time of 15 to 20 seconds in a solution consisting of $700 \mathrm{~mL}$ ethanol, $120 \mathrm{~mL}$ distilled water, $100 \mathrm{~mL}$ glycerol, and
$80 \mathrm{~mL}$ perchloric acid. This optimized sample-polishing steps insured an average indexing rate greater than $60 \mathrm{pct}$ even for the heavily deformed samples. The acquired EBSD dataset was analyzed using the TSL$\mathrm{OIM}^{\mathrm{TM}}$ (version 6.2) software. For low to medium deformed samples ( $\leq 70$ pct thickness reduction), the acquired EBSD map sizes were $150 \times 150 \mu \mathrm{m}$. For heavily deformed samples ( 90 pct reduction in thickness), several maps of dimensions approximately $50 \times 50 \mu \mathrm{m}$ were acquired using a fine scan step size of $50 \mathrm{~nm}$ for the purpose of determining the microstructural parameters and texture. At least 4000 grains of each phase were considered for calculating the texture. The ODFs were calculated from the EBSD scan data using the harmonic series expansion method of Bunge ${ }^{[18]}$ using series rank $L=22$ and Gaussian halfwidth $5 \mathrm{deg}$. Orthotropic sample symmetry for rolled specimens was assumed in calculating the ODFs. A cutoff angle of $15 \mathrm{deg}$ was used for calculating the fraction (defined by no. of points belonging to a certain component/total data points) of different texture components. This means that for a given component, any orientation which is less than $15 \mathrm{deg}$ misoriented from the given orientation will be considered within the given orientation. In the case of an overlap with multiple components, the orientation is assigned the component which has the least misorientation with the orientation.

\section{RESULTS}

\section{A. Evolution of Microstructure}

Figure 1(a) shows the phase map of the hot-rolled and homogenization-annealed DSS used as the starting material for further warm-rolling experiments. The volume fractions of the ferrite (red) and austenite (green) are almost equal $\sim 50$ pct in the starting material. The annealed microstructure shows that both the phases have an elongated morphology along the prior hotrolling direction (RD). The presence of annealing twins revealed by the annealing twin boundaries (blue) is noticed inside the recrystallized austenite grains. The starting average grain size of the ferrite and austenite expressed as thickness along the ND is very similar in this condition, $\sim 6 \mu \mathrm{m}$. A comparison of the $\Phi_{2}=45$ deg section of the ferrite (Figure 1(b)) with that of the $\Phi_{2}=45-\mathrm{deg}$ section showing the ideal locations of different texture components (Figure 1(c)) clearly reveals the presence of a strong ND-fiber $(\langle 111\rangle / / \mathrm{ND})$ component $\{111\}[11 \overline{2}]$ along with the minor presence of the cube component $(\{001\}\langle 100\rangle)$. The $\Phi_{2}=0-$, 45-, and 65-deg sections of the ODF of austenite along with the ideal locations of the typical texture components indicate a weak (maximum ODF intensity 3.86)

Table I. Chemical Composition of the Experimental DSS

\begin{tabular}{lccccccrrrr}
\hline Element & $\mathrm{C}$ & $\mathrm{S}$ & $\mathrm{Cr}$ & $\mathrm{Mn}$ & $\mathrm{Ni}$ & $\mathrm{P}$ & $\mathrm{Si}$ & $\mathrm{Mo}$ & $\mathrm{Fe}$ \\
\hline Weight percent & 0.08 & 0.001 & 24.18 & 0.14 & 10.5 & 0.017 & 0.45 & 3.11 & balance \\
\hline
\end{tabular}




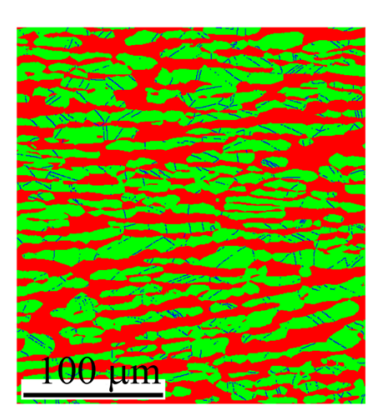

(a)

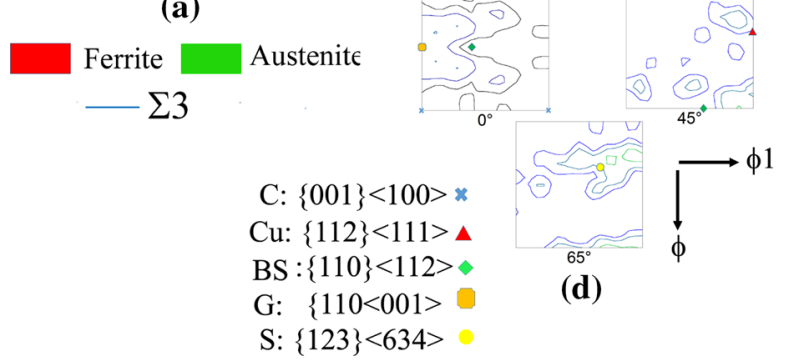

Fig. 1-(a) Phase map showing the distribution of ferrite and austenite in the homogenized DSS used as the starting material for subsequent warm rolling; $(b)$ and $(c)$ show the $\Phi_{2}=45$-deg section of the ODF of ferrite in the starting material and locations of the ideal components, respectively. $(d)$ shows the $\Phi_{2}=0-, 45-$, and 65-deg sections of the ODF of austenite along with the locations of ideal deformation texture components.

presence of typical pure metal- or copper-type texture in austenite.

Figure 2 shows the evolution of microstructure and texture during warm rolling at different warm-rolling temperatures up to $70 \mathrm{pct}$ reduction in thickness. The microstructures after 20 pct warm rolling at $698 \mathrm{~K}$ $\left(425^{\circ} \mathrm{C}\right)$ (Figure $\left.2(\mathrm{~d})\right)$ and $898 \mathrm{~K}\left(625^{\circ} \mathrm{C}\right)$ (Figure $2(\mathrm{~g})$ ) show more elongated morphology as compared to the warm-rolled microstructure at $498 \mathrm{~K}\left(225^{\circ} \mathrm{C}\right)$ (Figure 2(a)). With increasing deformation to 40 pet (Figures 2(b), (e), (h)) and 70 pct (Figures 2(c), (f), (i)) reduction in thickness, the microstructure gradually transforms into typical banded morphology characterized by the alternate arrangement of the elongated ferrite and austenite bands. It is clearly observed that after 70 pct warm rolling at different temperatures, the thickness of the bands is not uniform and varies from one end of the bands to the other end. However, as compared to the more continuous morphology observed after 70 pct warm rolling at $498 \mathrm{~K}\left(225^{\circ} \mathrm{C}\right)$ (Figure $2(\mathrm{c})$ ) and $898 \mathrm{~K}\left(625^{\circ} \mathrm{C}\right)$ (Figure 2(i)), the microstructures of the specimen 70 pct warm rolled at $698 \mathrm{~K}$ $\left(425^{\circ} \mathrm{C}\right.$ ) (Figure 2(f)) clearly show thick ferrite regions coexisting with rather thin and fragmented ferrite regions (indicated by arrows).

The structural evolution following 90 pet warm rolling at different temperatures is shown in Figure 3. Figure 3 also shows the grain boundary maps of the two constituent phases separately. The typical banded morphology is observed in all cases. The microstructure of material warm rolled at $498 \mathrm{~K}\left(225^{\circ} \mathrm{C}\right)$ (Figure 3(a)) shows well-developed lamellar structure although some regions show traces of grain fragmentation. Both ferrite (Figure 3(d)) and austenite (Figure 3(g)) bands are internally subdivided by HAGBs. The microstructure of the material warm rolled 90 pct at $698 \mathrm{~K}\left(425^{\circ} \mathrm{C}\right)$ (Figure 3(b)) is distinctly different from that observed after warm rolling at $498 \mathrm{~K}\left(225^{\circ} \mathrm{C}\right)$ (Figure 3(a)). The microstructure of 90 pct warm-rolled DSS at $698 \mathrm{~K}$ $\left(425^{\circ} \mathrm{C}\right)$ (Figure $3(\mathrm{~b})$ ) shows mechanical fragmentation or breakdown of the lamellar structure resulting in irregular morphology evidenced by the presence of thick ferrite blocks (Figure 3(e)). This is consistently observed throughout the microstructure of DSS 90 pct warm rolled at $698 \mathrm{~K}\left(425{ }^{\circ} \mathrm{C}\right)$. In order to support this observation, a phase map (Figure 3(j)) from another region of the $698 \mathrm{~K}\left(425^{\circ} \mathrm{C}\right)$ material and the corresponding orientation map of the ferrite fraction (Figure 3(k)) are shown. The phase map (Figure 3(j)) again clearly shows thick ferrite blocks (indicated by arrow) coexisting with regions with typical lamellar morphology (shown bounded by square). Interestingly, some of the thick ferrite regions (marked by arrow in Figure 3(e)) do not show further subdivision by high-angle boundaries (HAGBs defined by misorientation angle $\left.\left(\theta_{\text {mis }}\right)>15 \mathrm{deg}\right)$, but by the presence of low-angle boundaries (LAGBs defined by $2 \mathrm{deg} \leq \theta_{\text {mis }} \leq 15 \mathrm{deg}$ ) only. In sharp contrast, the microstructure of the material warm rolled to 90 pct reduction in thickness at $898 \mathrm{~K}\left(625^{\circ} \mathrm{C}\right)$ (Figure 3(c)) shows near perfect lamellar structure throughout the deformed volume almost free of thick ferrite blocks. Both the ferrite (Figure 3(f)) and austenite (Figure 3(i)) bands in the 90 pct warm-rolled material at $898 \mathrm{~K}\left(625^{\circ} \mathrm{C}\right)$ are very finely subdivided by extended HAGBs shown inset in Figures 3(f) and (i) for clarity.

Figure 4 summarizes the evolution of key structural parameters during warm rolling at different temperatures. 

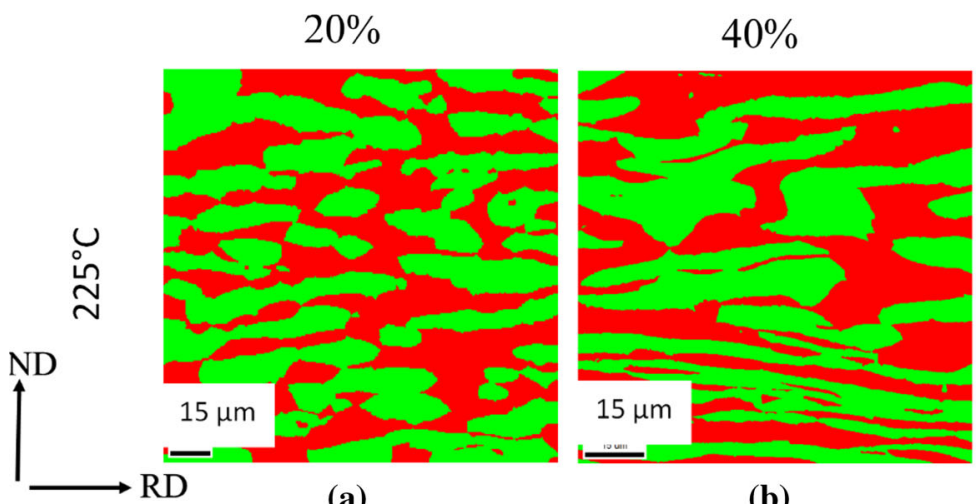

(b)

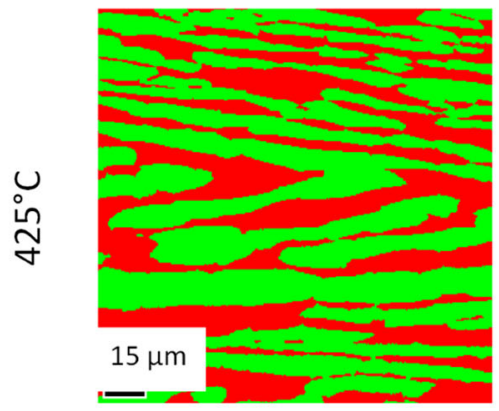

(d)

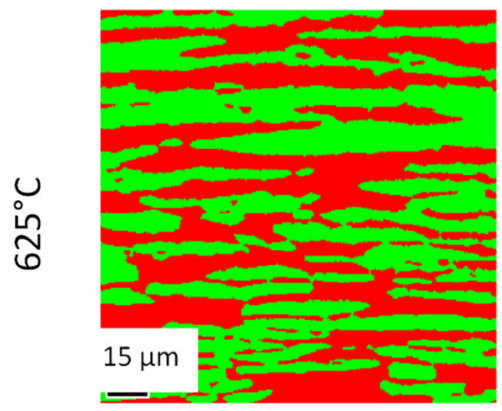

(g)

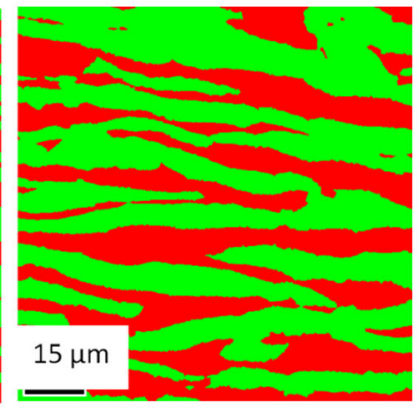

(e)

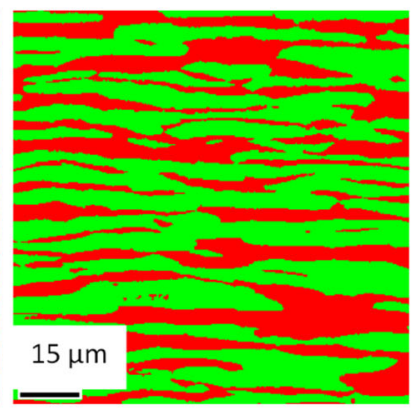

(h)

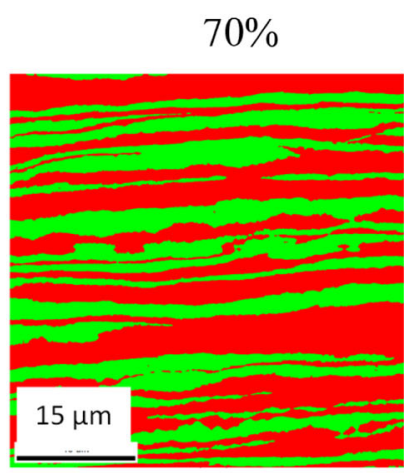

(c)

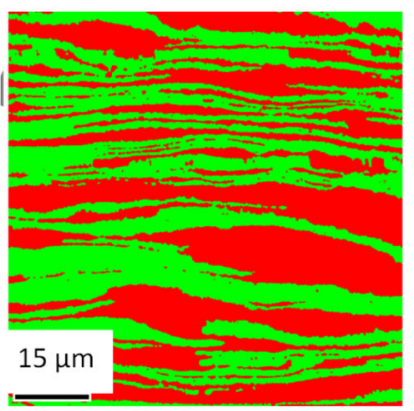

(f)

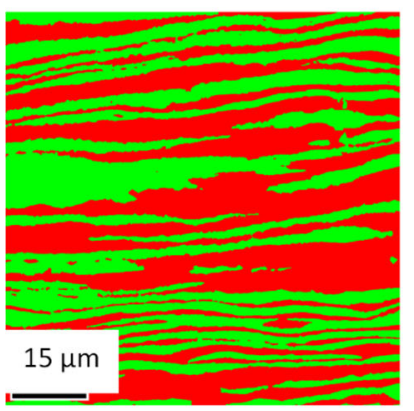

(i)

Fig. 2- Phase map of the DSS warm rolled at $225^{\circ} \mathrm{C}\left(\right.$ a) to $(c), 425{ }^{\circ} \mathrm{C}(d)$ to $(f)$, and $625^{\circ} \mathrm{C}(\mathrm{g})$ to $(i)$ up to 20 pct (a), (d), (g), 40 pct (b), (e), (h), and 70 pct (c), (f), (i) reduction in thickness.

The variation of the austenite phase fraction in the 90 pct warm-rolled materials at different temperatures is shown in Figure 4(a). The austenite phase fraction does not change significantly during warm rolling at different temperatures. The effect of strain and warm-rolling temperature on the two constituent phases is understood from the variation of the average thickness of the two phase bands (Figure 4(b)), HAGB fraction (Figure 4(c)), and HAGB spacing (Figure 4(d)) of the two phases. The average thickness of the two phases is similar (ferrite shows slightly higher value as compared to austenite) after $90 \mathrm{pct}$ warm rolling at $498 \mathrm{~K}$ $\left(225^{\circ} \mathrm{C}\right)$. Remarkably, the ferrite shows significantly higher average thickness $(>1 \mu \mathrm{m})$ as compared to the austenite $(\sim 0.5 \mu \mathrm{m})$ after warm rolling at $698 \mathrm{~K}$ $\left(425^{\circ} \mathrm{C}\right)$. The average thickness of the two phases is again found to be quite similar $(\sim 0.5 \mu \mathrm{m})$ after $90 \mathrm{pct}$ warm rolling at $898 \mathrm{~K}\left(625^{\circ} \mathrm{C}\right)$.
The ferrite phase usually shows lower HAGB fraction and higher HAGB spacing as compared to the austenite phase in the same warm-rolled DSS. The main point of concern, however, is the evolution of HAGB fraction and HAGB spacing in the two constituent phases following 90 pet warm rolling, which show remarkably different behavior. In the case of austenite, the HAGB fraction following 90 pct warm rolling increases consistently with increasing warm-rolling temperature. The average HAGB fraction in austenite at $498 \mathrm{~K}$ and $698 \mathrm{~K}$ $\left(225^{\circ} \mathrm{C}\right.$ and $\left.425^{\circ} \mathrm{C}\right)$ is $\sim 0.41$ and 0.45 , respectively, but increases to $\sim 0.57$ following 90 pct warm rolling at $898 \mathrm{~K}\left(625^{\circ} \mathrm{C}\right)$. The corresponding HAGB spacing values are $\sim 0.48,0.50$, and 0.31 . The HAGB fraction in ferrite after 90 pet warm rolling at $498 \mathrm{~K}\left(225^{\circ} \mathrm{C}\right)$ is $\sim 0.25$; however, in sharp contrast to austenite, remarkable decreases in the HAGB fraction are observed after 90 pet warm rolling at $698 \mathrm{~K}\left(425^{\circ} \mathrm{C}\right)(\sim 0.18)$, which is 


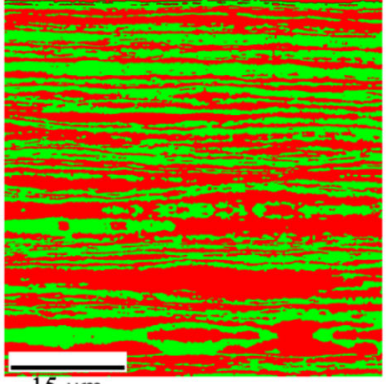

(a)

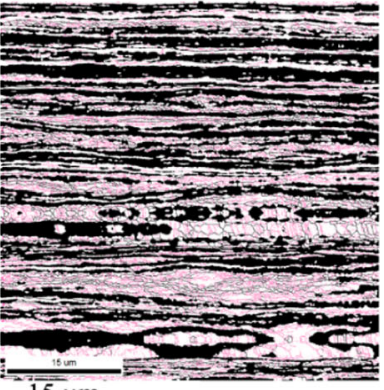

(d)

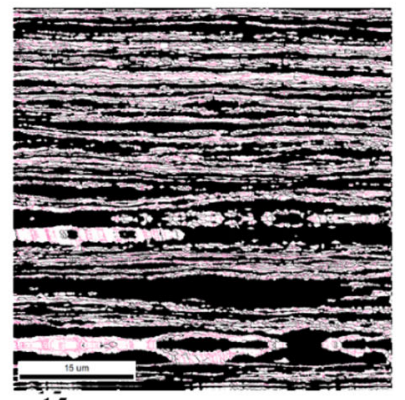

(g)

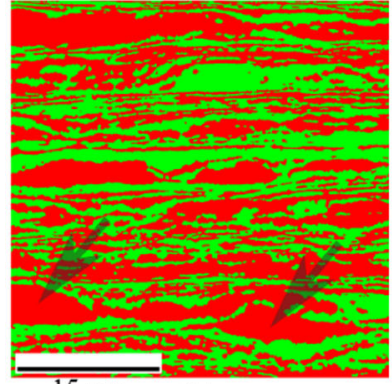

$15 \mu \mathrm{m} \quad$ (b)

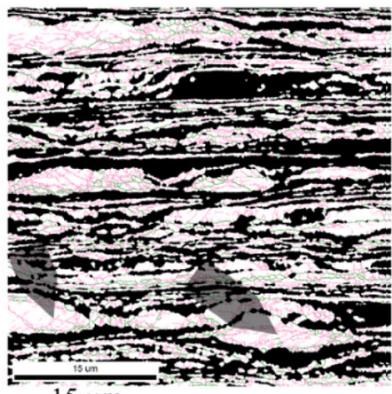

(e)

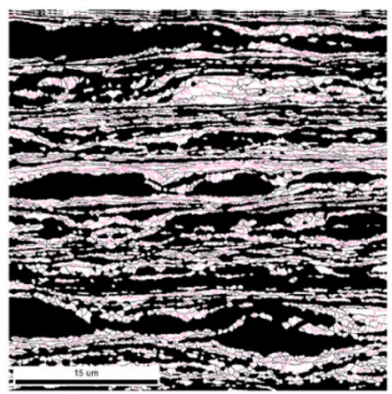

$15 \mu \mathrm{m} \quad$ (h)

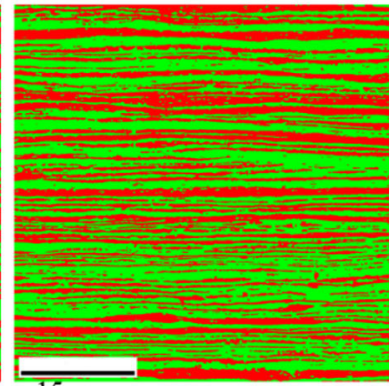

(c)

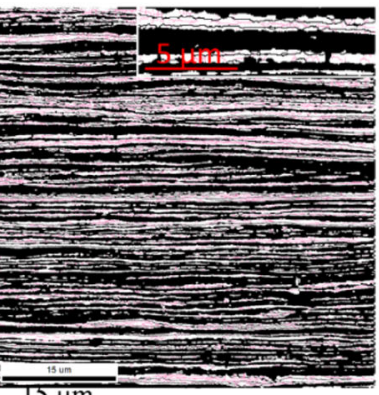

(f)

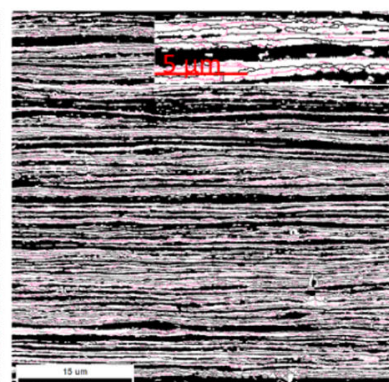

$15 \mu \mathrm{m}$

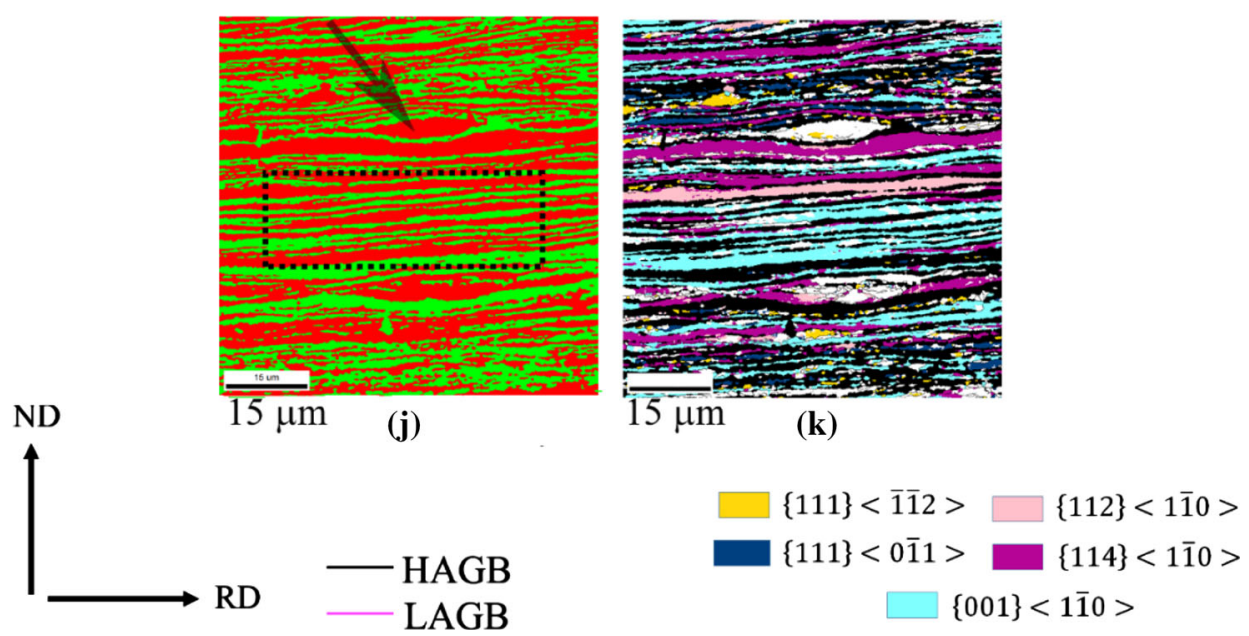

Fig. 3-Phase maps of the duplex steel 90 pct warm rolled at $(a) 498 \mathrm{~K}\left(225^{\circ} \mathrm{C}\right),(b) 698 \mathrm{~K}\left(425^{\circ} \mathrm{C}\right)$, and $(c) 898 \mathrm{~K}\left(625{ }^{\circ} \mathrm{C}\right) ;(d)$ to $(f)$ are the $\mathrm{GB}$ maps of the ferrite at $498 \mathrm{~K}\left(225^{\circ} \mathrm{C}\right), 698 \mathrm{~K}\left(425^{\circ} \mathrm{C}\right)$, and $898 \mathrm{~K}\left(625^{\circ} \mathrm{C}\right)$, respectively, while $(g)$ to $(i)$ are the corresponding $\mathrm{GB}$ maps of the austenite. Figures $3(j)$ and $(k)$ show the phase map and orientation map, respectively, of ferrite in DSS 90 pct warm rolled at $698 \mathrm{~K}\left(425^{\circ} \mathrm{C}\right)$ obtained from another region. 


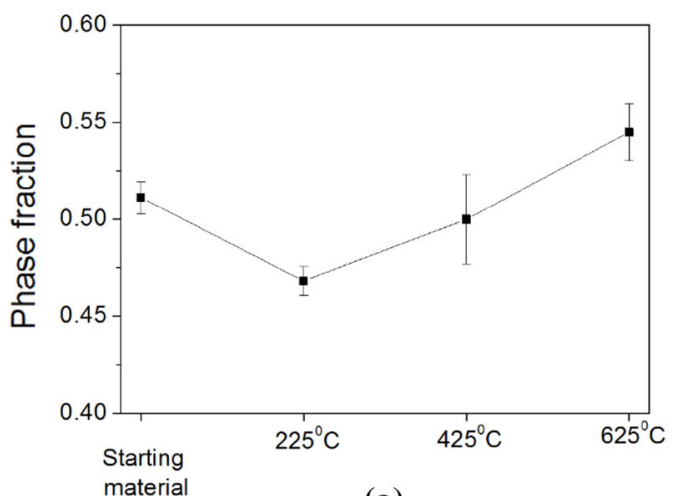

(a)

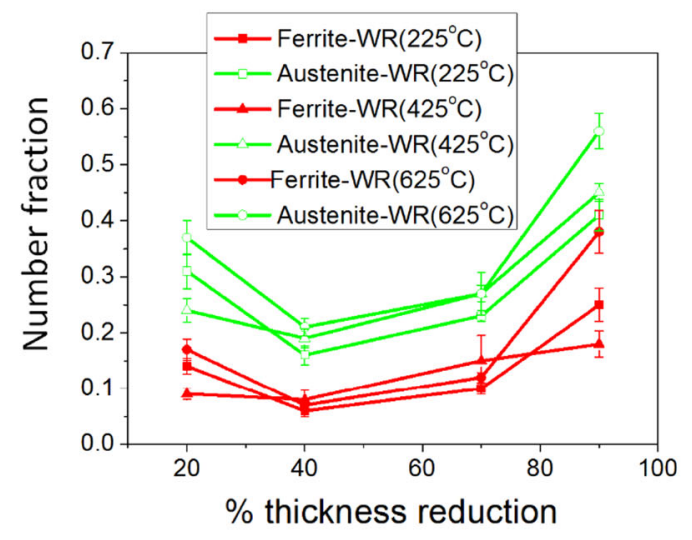

(c)

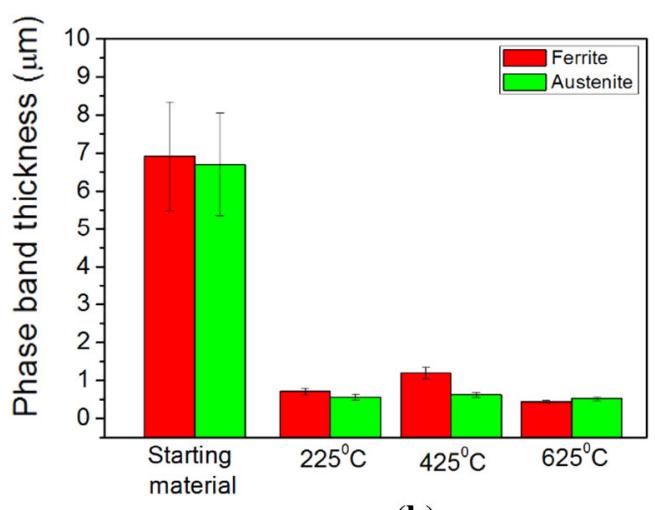

(b)

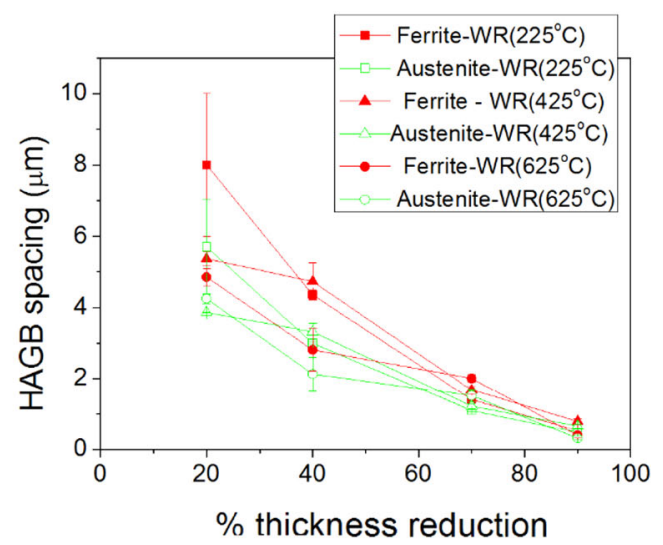

(d)

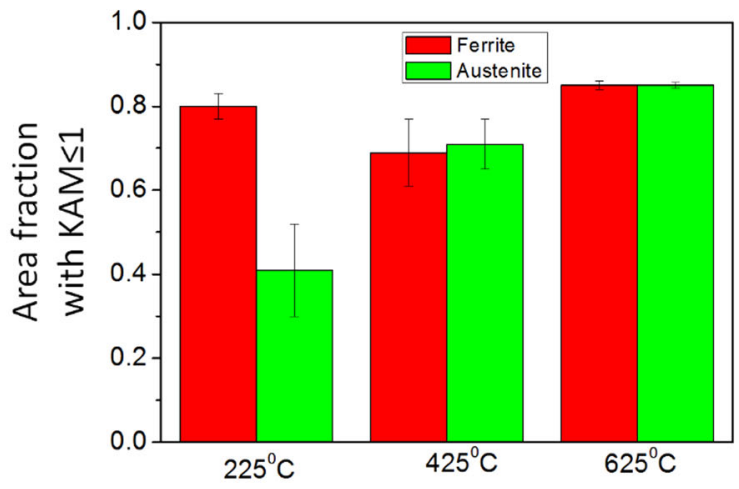

(e)

Fig. 4-Variation of $(a)$ austenite phase fraction and $(b)$ thickness of the phase bands after 90 pct warm rolling at different temperatures; $(c)$ and (d) show the variation of HAGB fraction and HAGB spacing, respectively, of the two phases with increasing deformation at different warm-rolling temperatures; $(e)$ shows the area fraction of the two phases in DSS 90 pct warm rolled at different temperatures having KAM $\leq 1$.

quite consistent with the presence of thick ferrite blocks internally free of HAGBs in this warm-rolled condition (Figure 3(b)). The HAGB spacing in ferrite in $498 \mathrm{~K}$ $\left(225^{\circ} \mathrm{C}\right.$ ) warm rolled is $\sim 0.54 \mu \mathrm{m}$ which is significantly lower than the HAGB spacing of the ferrite in DSS 90 pet warm rolled at $698 \mathrm{~K}\left(425^{\circ} \mathrm{C}\right)$. Significant increase in the HAGB fraction $(\sim 0.38)$ in ferrite is again observed after 90 pet warm rolling at $898 \mathrm{~K}\left(625^{\circ} \mathrm{C}\right)$ with accompanying decrease in the HAGB spacing to $\sim 0.39 \mu \mathrm{m}$.
Figure 4(e) shows the area fraction of the two phases having Kernel Average Misorientation (KAM) less than one calculated up to third nearest neighbor using binning $=20$. KAM is related to the internal misorientation and thus a low KAM value indicates misorientation free or recovered or recrystallized nature ${ }^{[19,20]}$ KAM values of austenite in DSS are found to be higher than ferrite in DSS at all deformation levels during warm rolling at $498 \mathrm{~K}$ $\left(225^{\circ} \mathrm{C}\right)$. However, the average KAM values are found to be quite similar for the two phases during warm rolling 


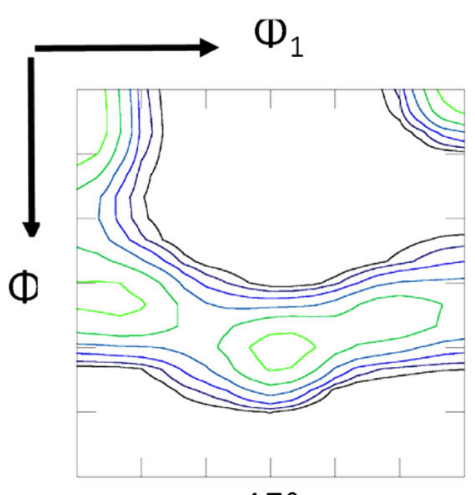

$45^{\circ}$

(a)
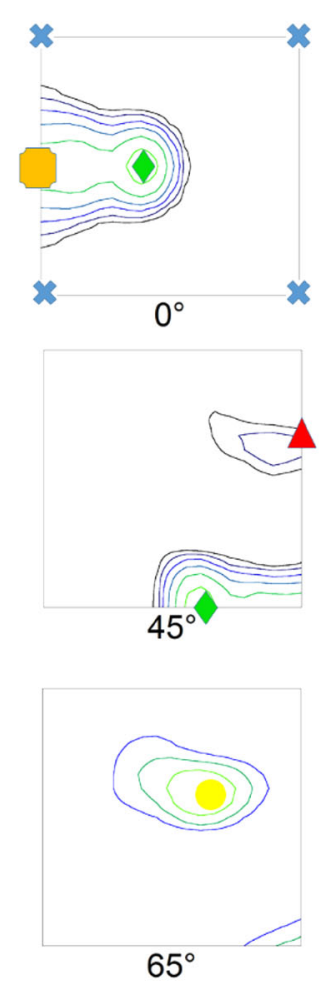

(d)

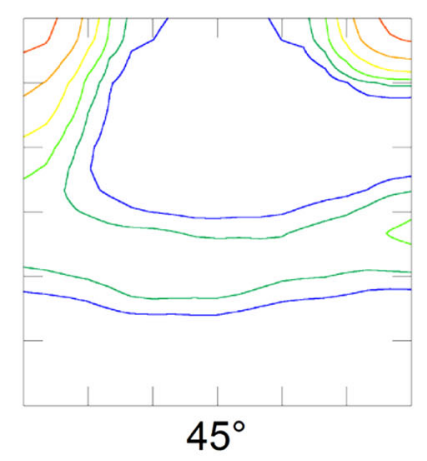

(b)
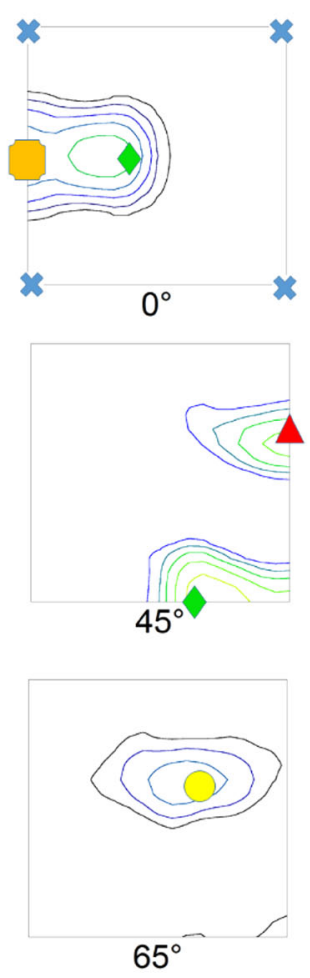

(e)

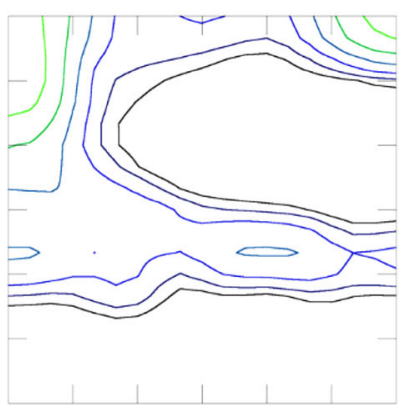

$45^{\circ}$

(c)
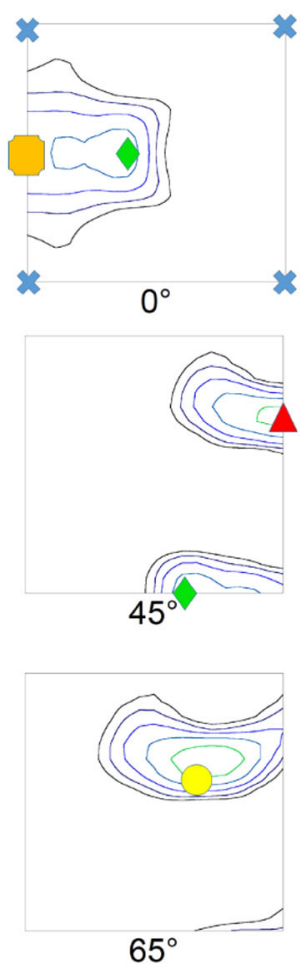

(f)

Fig. $5-\Phi_{2}=45$-deg section of the ODFs of ferrite in DSS 90 pct warm rolled at $($ a $) 498 \mathrm{~K}\left(225^{\circ} \mathrm{C}\right),(b) 698 \mathrm{~K}\left(425^{\circ} \mathrm{C}\right)$, and $(c) 898 \mathrm{~K}$ $\left(625{ }^{\circ} \mathrm{C}\right) .(d)$ to $(f)$ are the $\Phi_{2}=0-, 45-$, and 65 -deg sections of the ODFs of austenite in DSS 90 pct warm rolled at (d) $498 \mathrm{~K}\left(225^{\circ} \mathrm{C}\right)$, (e) $698 \mathrm{~K}\left(425^{\circ} \mathrm{C}\right)$, and (f) $898 \mathrm{~K}\left(625^{\circ} \mathrm{C}\right)$, respectively. Intensities of the contour lines of the ODFs and symbols used are the same as in Fig. 1.

carried out at $698 \mathrm{~K}$ and $898 \mathrm{~K}\left(425^{\circ} \mathrm{C}\right.$ and $\left.625^{\circ} \mathrm{C}\right)$. This results in the area fraction of austenite having KAM $\leq 1$ being significantly lower than the area fraction of ferrite in DSS 90 pct warm rolled at $498 \mathrm{~K}\left(225^{\circ} \mathrm{C}\right)$. However, the area fraction of the two phases having $\mathrm{KAM} \leq 1$ is found to be rather high, but very similar following 90 pet deformation at higher warm-rolling temperatures.

\section{B. Evolution of Texture}

The evolution of texture in the DSS is shown qualitatively in Figure 5 which shows the $\Phi_{2}=45$-deg sections of the ODFs of the ferrite (Figures 5(a) to (c)) and $\Phi_{2}=0-, 45-$, and 65-deg sections of ODF of austenite (Figures 5(d) to (f)) in 90 pct warm-rolled materials processed at different temperatures along with the locations of ideal texture components. The texture results shown in Figure 5 for the DSS warm rolled at different temperatures are obtained by merging several EBSD scans in each case so as to insure that orientations of at least 4000 grains of each phase are considered for obtaining statistically reliable and consistent texture results. The ODF sections (Figures 5(a) to (c)) clearly show the presence of the two well-known texture fibers, 


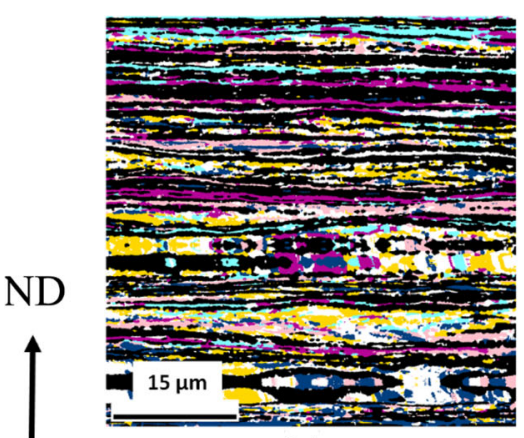

(a)
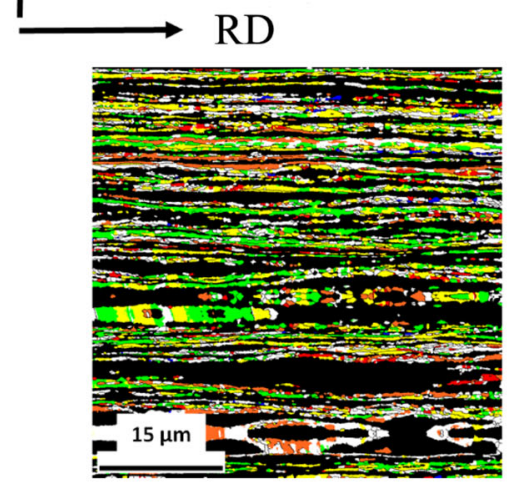

(d)

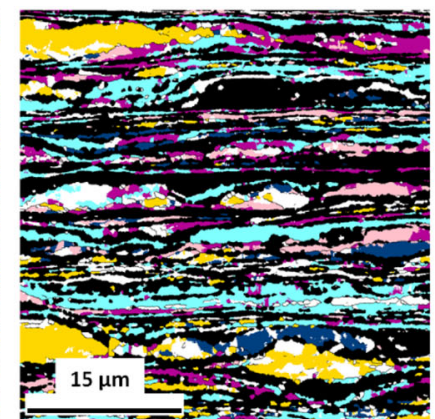

(b)

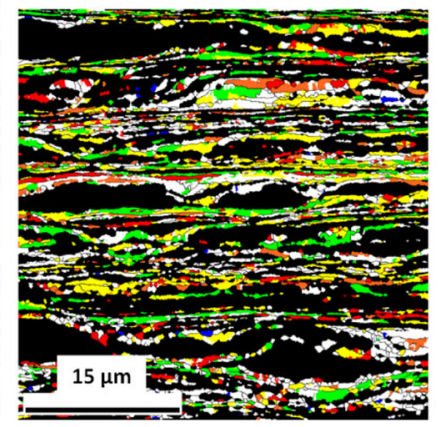

(e)

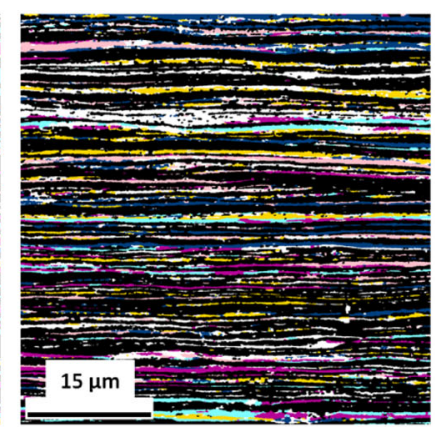

(c)

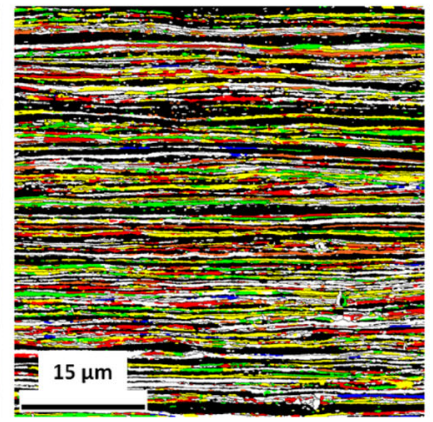

(f)
Ferrite

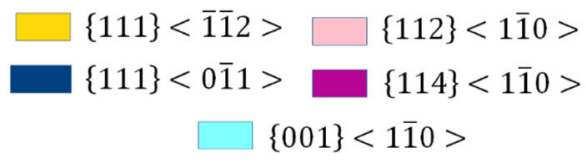

Austenite

Cube: $\{001\}<100>$

BS: $\{110\}<112>$
$\mathrm{Cu}: \quad\{112\}<111>$

S: $\quad\{123\}<634>$

G: $\{011\}<100>$

.

Fig. 6 - Orientation maps of ferrite $(a)$ to $(c)$ and austenite $(d)$ to $(f)$ in DSS 90 pct warm rolled at $498 \mathrm{~K}\left(225{ }^{\circ} \mathrm{C}\right)\left(\right.$ a) to (d), $698 \mathrm{~K}\left(425{ }^{\circ} \mathrm{C}\right)(\mathrm{b})$ to (e), and $898 \mathrm{~K}\left(625^{\circ} \mathrm{C}\right)$ (c) to (f).

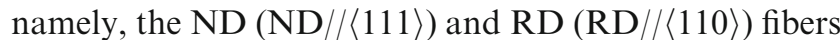
in ferrite. The spatial distribution of different texture components is shown in the representative orientation maps in Figure 6. It is to be noted that the orientation maps shown in Figure 6 are obtained from the same EBSD scans used to construct the previously shown maps of the 90 pct warm-rolled materials at different temperatures (Figure 3). The variation of different texture components with warm-rolling temperatures is summarized in a quantitative manner in Figure 7(a). Figure 7(a) represents the average value of each texture component in ferrite calculated from several EBSD scans.

The strong components along the RD-fiber in the 90 pct warm-rolled material at $498 \mathrm{~K}\left(225^{\circ} \mathrm{C}\right)$ are (001) $[1 \overline{1} 0]$ (highlighted in aqua in the orientation maps in Figures 6(a) to (c)), (114) [110] (highlighted in purple in the orientation maps in Figures 6(a) to (c)), and (112) [1 $1 \overline{1} 0]$ (highlighted in pink in the orientation maps in Figures 6(a) to (c)) having very similar fractions between $\sim 12$ to 14 pct. The strongest component along the ND-fiber is (111)[11 2 ] (highlighted in gold in the orientation maps in Figures 6(a) to (c)) $\sim 16$ pct. The fraction of the (111)[011] (highlighted in deep blue) is $\sim 13$ pct. The total fraction of the ND-fiber components $\sim 30 \mathrm{pct}$ is found to be decidedly lower than the RD-fiber components $\sim 40$ pct. These values may be compared with the respective fractions of the ND- and RD-fibers $\sim 30$ and 6 pct, respectively, in the starting material, which clearly show a slight decrease in the total fraction of the ND-fiber components, but a significantly large increase in the total fraction of the RD-fiber components (Figure 7(a)).

Warm rolling of DSS at $698 \mathrm{~K}\left(425^{\circ} \mathrm{C}\right)$ results in remarkable strengthening of the RD-fiber, but further weakening of the ND-fiber in ferrite as compared to the ferrite in DSS warm rolled at $498 \mathrm{~K}\left(225^{\circ} \mathrm{C}\right)$. This is evident from the intensity distribution in the ODF section (Figure 5(b)), orientation map shown in Figure 6(b), and the fraction of different components (Figure 7(a)). The fractions of the RD-fiber components (001)[110] and (114) [1 $\overline{1} 0]$ are $\sim 40$ and 16 pct, respectively, and the total fraction of the RD-fiber components is $\sim 55$ pct which is much higher than the total fraction of the ND-fiber components, $\sim 18$ pct. Very similar observations are made from the orientation map (Figure 3(k)) obtained from the ferrite fraction of the other scan area. The fractions of the RD-fiber components (001)[110] and (114)[110], $\sim 33$ and 28 pct, respectively, are much higher than the fractions of (111)[112] 

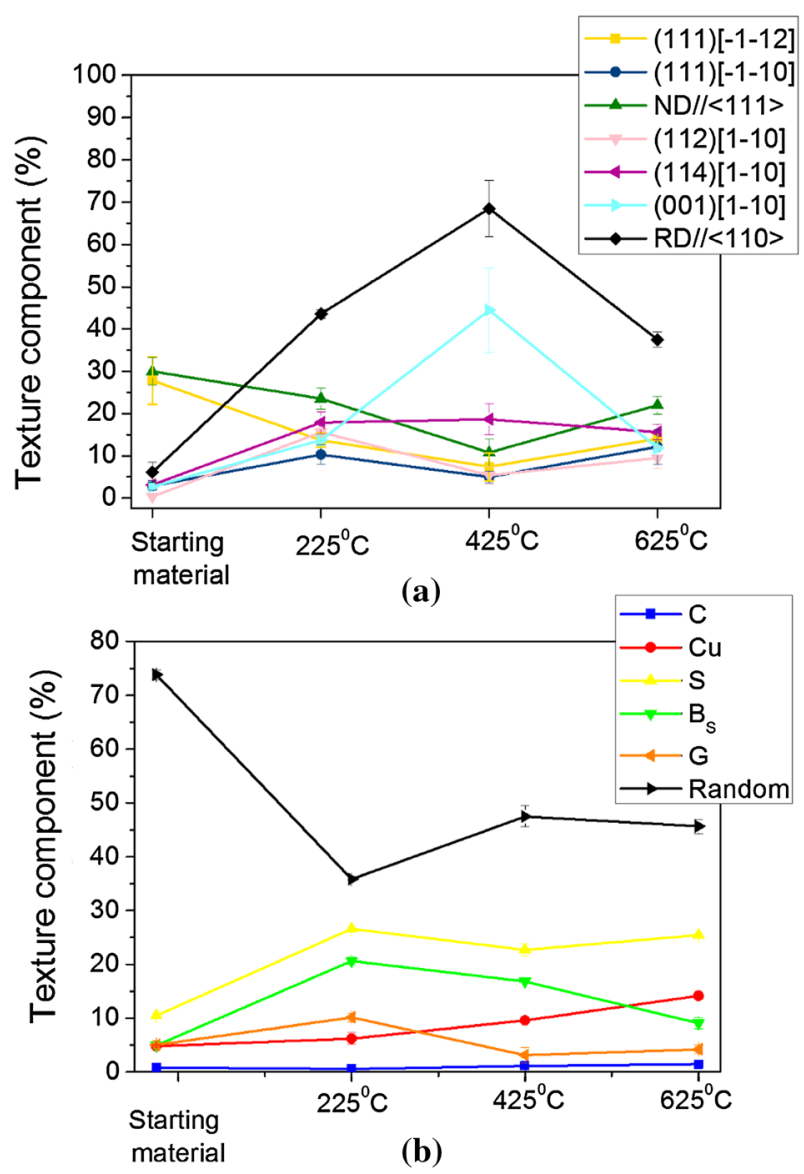

Fig. 7-Variation of texture components in (a) ferrite and $(b)$ austenite in DSS 90 pct warm rolled at different temperatures.

and (111) $[0 \overline{1} 1]$ components, $\sim 3$ and 6 pct, respectively. The fractions of the different texture components are averaged over a large no. of scan areas and are shown in Figure 7(a) for the ferrite phase in the DSS 90 pct warm rolled at $698 \mathrm{~K}\left(425^{\circ} \mathrm{C}\right)$. The average fraction of the RD-fiber components (114) [1 $\overline{10}]$ and $(001)[1 \overline{1} 0]$ is $\sim 19$ and 45 pct, respectively, and the total fraction of the RD-fiber components is $\sim 68$ pct which is much higher than the total average fraction of the ND-fiber components $(\sim 10$ pct $)$.

The $\Phi_{2}=45$-deg section of the ODF of ferrite in DSS after 90 pet warm rolling at $898 \mathrm{~K}\left(625^{\circ} \mathrm{C}\right)$ (Figure 5(c)) shows the presence of both the fiber components. Remarkably, the texture of the ferrite phase shows a stark reversal in trend after 90 pet warm rolling at $898 \mathrm{~K}\left(625^{\circ} \mathrm{C}\right)$, such that the fraction of the ND-fiber ( 25 pct) is increased, but that of the RD-fiber ( $\sim 40 \mathrm{pct})$ is diminished remarkably as compared to the $698 \mathrm{~K}\left(425^{\circ} \mathrm{C}\right)$ warm-rolled condition (Figure $7(\mathrm{a})$ ). The decrease in the fraction of the RD-fiber appears to be primarily due to the decrease in the fraction of the (001) $[1 \overline{1} 0]$ and (114) $[1 \overline{1} 0]$ components to $\sim 11$ and 13 pct, respectively. Development of a weak $\{001\}\langle 100\rangle$ component can also be noticed in the ODF section of the ferrite in DSS warm rolled at $898 \mathrm{~K}$ $\left(625^{\circ} \mathrm{C}\right)$ (Figure $\left.5(\mathrm{c})\right)$. The texture of ferrite in DSS warm rolled at $898 \mathrm{~K}\left(625^{\circ} \mathrm{C}\right)$ (Figure $5(\mathrm{c})$ ) is also slightly weaker than that of the $498 \mathrm{~K}\left(225^{\circ} \mathrm{C}\right)$ warmrolled material (Figure 5(a)).

In contrast, the texture evolution in the austenite during warm rolling at different temperatures appears to be quite similar. The appearance of the $\Phi_{2}=0-, 45-$, and 65-deg sections of the ODFs (Figures 5(d) to (f)) obtained from the austenite at different warm-rolling temperatures clearly shows the development of a typical pure metal- or copper-type texture characterized by the presence of typical $\beta$-fiber orientations, namely, copper or $\mathrm{Cu}$ $(\{112\} \mathrm{G}\langle 111\rangle$; highlighted in red), S $(\{123\}\langle 634\rangle$, highlighted in yellow), and brass or $\mathrm{B}_{\mathrm{S}}(\{110\}\langle 112\rangle$, highlighted in green) (Figures 6(d) to (f)). The strongest component of the deformation texture at different warmrolling temperatures is the $\mathrm{S}$ component having an average fraction $\sim 25$ pct (Figure 7(b)). The fraction of the $\mathrm{B}_{\mathrm{S}}$ component is higher $(-20 \mathrm{pct})$ than that of the $\mathrm{Cu}$ component $(\sim 10 \mathrm{pct})$ in the $498 \mathrm{~K}\left(225^{\circ} \mathrm{C}\right)$ warm-rolled material. However, the fraction of the $\mathrm{Cu}$ component increases and that of the $\mathrm{B}_{\mathrm{S}}$ component decreases consistently with increasing the temperature of warm rolling (Figure 7(b)). Goss or G component $(\{011\}\langle 100\rangle$, highlighted in orange) is present only in minor proportion at higher warm-rolling temperatures (Figure 7(b)).

\section{DISCUSSION}

\section{A. Evolution of Microstructure}

The volume fraction of austenite in DSS following 90 pct warm rolling at different temperatures is found to vary from 45 to $55 \mathrm{pct}$, i.e., very close to the volume fraction of austenite $(-50 \mathrm{pct})$ in the starting material used for the warm-rolling experiments. This clearly indicates that austenite is very stable during warm rolling and the effect of any stress-induced phase transformation on the development of microstructure and texture can be ruled out.

The average thickness of the two constituent phases at different rolling temperatures is indicative of strain partitioning between the two phases (Figure 4(b)). After 90 pet warm rolling at $498 \mathrm{~K}\left(225^{\circ} \mathrm{C}\right)$ and $898 \mathrm{~K}$ $\left(625^{\circ} \mathrm{C}\right)$, the thickness of the two phases is found to be similar. Since the starting average grain sizes of the two phases are also quite similar (Figure 1(a)), it is easily concluded that strain partitions rather equally at these two warm-rolling temperatures. Thus, strain partitioning behavior at these two warm-rolling temperatures is similar to that observed during cold rolling of DSS. ${ }^{[2]}$ However, at the intermediate warm-rolling temperature at $698 \mathrm{~K}\left(425^{\circ} \mathrm{C}\right)$, the average thickness of austenite is found to be significantly lower than that of the ferrite (Figure 4(b)). This indicates that strain partitions more to austenite as compared to ferrite at this temperature, or in other words ferrite is the harder among the two phases. It may be noted that the microstructure at this temperature is characterized by remarkable inhomogeneity and the presence of fragmented ferrite regions (Figures 3(b), (e), (h), (j)).

The observed differences in the microstructure evolution at the intermediate warm-rolling temperature of 
$698 \mathrm{~K}\left(425^{\circ} \mathrm{C}\right)$ appear to be strongly affected by dynamic strain aging in single-phase ferrite ${ }^{[20]}$ and ferrite in $\operatorname{DSS}^{[21]}$ due to which the flow stress rises. It may be noted that the warm-rolling temperature of $698 \mathrm{~K}\left(425^{\circ} \mathrm{C}\right)$ is well within the observed dynamic strain aging temperature range in DSS, ${ }^{[21,22]}$ so that the effect will be much stronger in comparison to the two end temperatures of warm rolling. This would lead to increased hardness of ferrite, and difference in hardness of the two phases would lead to strain being partitioned more to austenite resulting in the average thickness of austenite phase bands being less than that of the ferrite bands also observed experimentally. The increased hardness of ferrite would further result in the suppression of grain subdivision due to the process of slip, ${ }^{[23,24]}$ but increased mechanical fragmentation of grains at the vicinity of phases' interfaces. Remarkably low HAGB fraction and fragmented microstructure observed after 90 pct warm rolling at $698 \mathrm{~K}\left(425^{\circ} \mathrm{C}\right)$ are in very good agreement with the above observations. In contrast, the microstructures at the two end warm-rolling temperatures show characteristics of more grain subdivision (finely subdivided structure in both the phases) ${ }^{[23,24]}$ and much less mechanical fragmentation of grains.

It is clearly observed that austenite shows significantly higher HAGB fraction and smaller HAGB spacing as compared to ferrite in the same warm-rolled condition. The austenite in the 90 pct warm-rolled material at $498 \mathrm{~K}\left(225^{\circ} \mathrm{C}\right)$ shows higher HAGB fraction, lower HAGB spacing, and also having much lower area fraction having KAM $\leq 1$ (Figure 4(e)) as compared to the ferrite which clearly reveals that recovery is much less in austenite as compared to ferrite at this warmrolling temperature. This is also consistent with average KAM values of austenite at all deformation levels being higher than that of ferrite at this warm-rolling temperature. The area fractions of the two phases having $\mathrm{KAM} \leq 1$ are quite high, but similar after 90 pct warm rolling at $698 \mathrm{~K}$ and $898 \mathrm{~K}\left(425^{\circ} \mathrm{C}\right.$ and $\left.625^{\circ} \mathrm{C}\right)$. This indicates that dynamic recovery happens in both the phases at these warm-rolling temperatures and the extent of dynamic recovery is also comparable in the two phases. This is again consistent with the fact that the average KAM values of the two phases at different deformation levels at these two warm-rolling temperatures are similar. Therefore, dynamic recovery should affect the microstructural evolution in the two phases to a similar extent. The finer microstructure of austenite but area fraction having $\mathrm{KAM} \leq 1$ similar to that of ferrite even after 90 pct warm-rolling at $898 \mathrm{~K}\left(625^{\circ} \mathrm{C}\right)$ indicates that the tendency to undergo the process of grain subdivision is more in austenite as compared to ferrite leading to a finer microstructure in the former (lower HAGB spacing and higher HAGB fraction) after warm-rolling at different temperatures.

\section{B. Evolution of Texture}

The austenite in the DSS consistently shows pure metal- or copper-type deformation texture after warm rolling at different temperatures. This is in sharp contrast to austenite in DSS and also single-phase austenitic steels which develop predominantly brass/ alloy-type texture after heavy cold rolling. ${ }^{[2]}$ The development of brass- or alloy-type deformation texture in austenite is related to the usually low SFE. Lowering of SFE results in the gradual transition of texture from pure metal-type to a predominantly brass/alloy-type texture with increasing deformation. ${ }^{[25,26]}$ This phenomenon of texture transition has been attributed to the occurrence of deformation twins, which becomes an important deformation mode in addition to the deformation by slip in low SFE materials. ${ }^{[27]}$

The gradual evolution of a pure metal-type texture in the austenite phase with increasing deformation indicates suppression of deformation twinning due to the increasing SFE with the increasing temperature of warm rolling. ${ }^{[28,29]}$ Although the SFE value of the present DSS has not been measured experimentally, for a Fe-10.7 pct Ni-18.3 pet $\mathrm{Cr}$ alloy, a twofold increase in SFE to $\sim 31 \mathrm{~mJ} / \mathrm{m}^{2}$ is noticed at $598 \mathrm{~K}\left(325^{\circ} \mathrm{C}\right)$ from a low SFE value of $\sim 16 \mathrm{~mJ} / \mathrm{m}^{2}$ in the deformed condition at room temperature ${ }^{[29]}$ In the present case, the increase in SFE is clearly evidenced by the strengthening of the pure metal-type character, i.e., consistent strengthening of the $\mathrm{Cu}$ component and weakening of the $B_{\mathrm{S}}$ component with increasing warm-rolling temperature. This is also supported by the fact that during cold rolling of the present DSS at room temperature there is a clear transition from pure metal-type texture to a predominantly brass-type texture (Figure 8). This is clearly understood from the relevant ODF sections of the coldrolled materials (Figure 8) which reveal that strength of the $\mathrm{B}_{\mathrm{S}}$ component increases with increasing thickness reduction, while strength of the $\mathrm{Cu}$ component is diminished during cold rolling (Figure 8). Although direct experimental evidence of deformation twins could

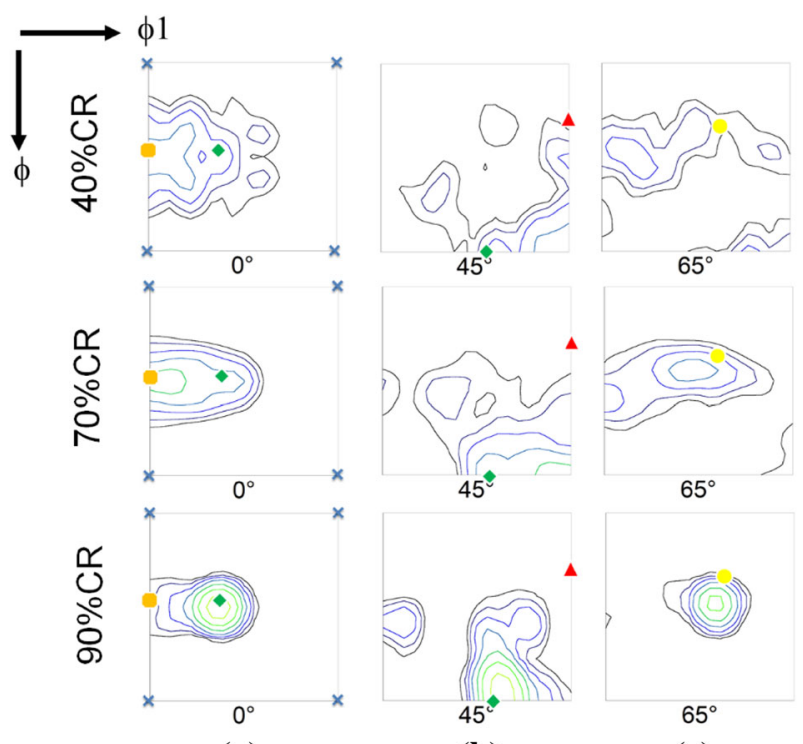

(a)

(b)

(c)

Fig. 8- $\Phi_{2}=0-, 45-$, and 65-deg sections of the ODFs of austenite in DSS cold rolled at room temperature to (a) 40 pct, (b) 70 pct, and (c) 90 pct reduction in thickness. The intensity of the contour lines and the symbols used are the same as in Fig. 1. 
not be obtained through EBSD, in the light of observed texture transition, it is most reasonable to assume that formation of deformation twins is prevalent in austenite during cold rolling owing to the low SFE. ${ }^{[30]}$

The texture of cold-rolled single-phase ferrite is usually described by the development of two prominent fibers, the RD- $(\langle 011\rangle / / \mathrm{RD})$ and the ND-fibers $(\langle 111\rangle / /$ ND), which strengthen with increasing deformation. ${ }^{[31]}$ The bulk texture of the warm-rolled single-phase ferrite has been studied by Barnett and Jonas who have found that the warm-rolling texture is very similar to coldrolled materials characterized by the presence of the above two fibers. Increase in warm-rolling temperature further sharpens the texture particularly for low carbon grades of steels. ${ }^{[15,32]}$ Development of texture in the ferrite phase of the DSS alloy during warm rolling clearly shows the existence of these two major fibers (Figures 5(a) to (c)). However, the RD-fiber is strengthened with increasing warm-rolling temperature up to $698 \mathrm{~K}\left(425^{\circ} \mathrm{C}\right)$ before decreasing after warm rolling at $898 \mathrm{~K}\left(625^{\circ} \mathrm{C}\right)$ (Figure $\left.7(\mathrm{a})\right)$. Exactly the opposite behavior is observed for the ND-fiber.

The texture development in the present DSS is also strongly affected by dynamic strain aging which is already observed in the case of microstructure development. It has been shown that slip is retarded on selected slip systems $(\{110\}\langle 111\rangle)$ due to dislocation pinning resulting in the strengthening of the RD-fiber components $\{001\}\langle 110\rangle$ and $\{112\}\langle 110\rangle$ at the expense of NDfiber component $\{111\}\langle 112\rangle .^{[33,34]}$ The presence of strong RD- and ND-fibers after warm rolling at $498 \mathrm{~K}$ and $898 \mathrm{~K}\left(225^{\circ} \mathrm{C}\right.$ and $\left.625^{\circ} \mathrm{C}\right)$ is consistent with the limited dynamic strain aging effect at these two temperatures. However, the strength of the RD-fiber component is maximum, while that of the ND-fiber component is minimum after 90 pet warm rolling at $698 \mathrm{~K}\left(425^{\circ} \mathrm{C}\right)$ due to dislocation pinning owing to a very strong dynamic strain aging effect.

Nevertheless, the main characteristics of the deformation texture of single-phase materials are retained by the constituent phases in the DSS alloy during warm rolling. In other words, the presence of the other phase does not appear to remarkably affect the development of texture in the two phases in DSS during warm rolling; however, the temperature of warm rolling greatly affects the microstructure and texture development of the two phases. In effect, the two constituent phases tend to behave independent of one another These observations are in excellent agreement with the study of Keichel et al ${ }^{[2]}$ on texture evolution during cold rolling of DSS, who argued that the major strain accommodation takes place at the phase boundaries along the RD and since these phase boundaries along RD are much lower in comparison to the phase boundaries along the ND, the two phases are deformed independent of one another and the end texture will be similar to the respective single-phase materials.

\section{CONCLUSIONS}

1. The development of microstructure having an alternate arrangement of ferrite and austenite bands is observed during warm rolling of DSS at different temperatures.

2. Inhomogeneous microstructure consisting of thick ferrite bands and fragmented ferrite regions along with more lamellar regions is observed at the intermediate warm-rolling temperature of $698 \mathrm{~K}$ $\left(425^{\circ} \mathrm{C}\right)$ as compared to the two end temperatures of warm rolling $\left[498 \mathrm{~K}\right.$ and $898 \mathrm{~K}\left(225^{\circ} \mathrm{C}\right.$ and $\left.625^{\circ} \mathrm{C}\right)$ ]. These differences in microstructure are also accompanied by remarkable differences in texture. While the texture of ferrite in warm-rolled DSS is characterized by the presence of RD- and ND-fiber components, ferrite in DSS 90 pct warm rolled at $698 \mathrm{~K}\left(425^{\circ} \mathrm{C}\right)$ shows a distinctly different behavior characterized by much higher fraction of the RD-fiber components as compared to the NDfiber components.

3 . The differences in microstructure and texture of ferrite in DSS warm rolled at $698 \mathrm{~K}\left(425^{\circ} \mathrm{C}\right)$ are attributed to stronger interaction of carbon atoms with dislocations and subsequent locking of dislocations at this temperature as compared to the two other warm-rolling temperatures.

4. Austenite in DSS following 90 pet warm rolling at different temperatures develops a pure metal- or copper-type texture in sharp contrast to a predominantly brass-type texture after cold rolling at room temperature. This is attributed to the slip being preferred over the formation of deformation twins during warm rolling due to increase in SFE with increasing temperature.

5. The microstructure and texture of the two constituent phases in DSS during warm rolling are significantly affected by warm-rolling temperature, but not significantly by the presence of the other phase.

\section{ACKNOWLEDGMENTS}

The authors would like to gratefully acknowledge Dr. G. Malakondaiah, former Director, DMRL, Hyderabad, for his kind permission to prepare the starting alloy used in the present research work using the facilities at DMRL, Hyderabad, and Dr. Raghu and Mr. Satheesh, scientists at DMRL, Hyderabad, for their kind support in preparing the experimental alloy. Helpful discussion with Professor N. Tsuji of Kyoto University, Japan, is also gratefully acknowledged.

\section{REFERENCES}

1. J. Keichel, J. Foct, and G. Gottstein: ISIJ Int., 2003, vol. 43, pp. 1788-94.

2. J. Keichel, J. Foct, and G. Gottstein: ISIJ Int., 2003, vol. 43, pp. 1781-87.

3. J. Keichel, G. Gottstein, and J. Foct: High Nitrogen Steels '98, 1999, vol. 318-23, pp. 785-91.

4. A. Belyakov, Y. Kimura, and K. Tsuzaki: Acta Mater., 2006, vol. 54, pp. 2521-32. 
5. M. Blicharski, J. Jura, T. Baudin, R. Penelle, J. Bonarski, and M. Kowalski: Arch. Metall. Mater., 2005, vol. 50, pp. 495-502.

6. K.E. Cooke, S. Yang, C. Selcuk, A. Kennedy, D.G. Teer, and D. Beale: Surf. Coat. Technol., 2004, vol. 188, pp. 697-702.

7. J. Rys and W. Ratuszek: Appl. Cryst. XXI, 2010, vol. 163, pp. 14550 .

8. J. Ryś and A. Zielińska-Lipiec: Arch. Metall. Mater., 2012, vol. 57, pp. 1041-53.

9. J. Rys and M. Witkowska: Appl. Cryst. XXI, 2010, vol. 163, pp. $151-56$.

10. J. Hamada and N. Ono: Mater. Trans., 2010, vol. 51, pp. 635-43.

11. J. Rys, W. Ratuszek, and M. Witkowska: Arch. Metall. Mater., 2005, vol. 50, pp. 857-70.

12. J. Rys, W. Ratuszek, and M. Witkowska: Appl. Cryst. XX, 2007, vol. 130 , pp. $57-62$.

13. M.R. Toroghinejad, A.O. Humphreys, F. Ashrafizadeh, A. Najafizadeh, and J.J. Jonas: Mater. Sci. Forum, 2003, vols. 426-4, pp. 3691-96.

14. R.K. Ray and A. Haldar: Mater. Manuf. Process., 2002, vol. 17, pp. $715-29$.

15. M.R. Barnett and J.J. Jonas: ISIJ Int., 1999, vol. 39, pp. 856-73.

16. A. Belyakov, R. Kaibyshev, Y. Kimura, and K. Tsuzaki: Mater. Sci. Forum, 2010, vols. 638-642, pp. 1905-10.

17. F.J. Humphreys and M. Hatherly: Recrystallization and Related Annealing Phenomena, 2nd ed., Elsevier, Oxford, 2004.

18. H.J. Bunge: Mathernatische Methoden der Texturanalyse, Academic Press, Berlin, 1969.
19. X.L. Li, W. Liu, A. Godfrey, D.J. Jensen, and Q. Liu: Acta Mater., 2007, vol. 55, pp. 3531-40.

20. G.E. Dieter: Mechanical Metallurgy, 2nd ed., McGraw-Hill Book Co., New York, NY, 1976.

21. S. Hereñú, I. Alvarez-Armas, and A.F. Armas: Scripta Mater., 2001, vol. 45, pp. 739-45.

22. D.A. Hughes and N. Hansen: Acta Mater., 1997, vol. 45, pp. $3871-86$.

23. D.A. Hughes and N. Hansen: Philos. Mag., 2003, vol. 83, pp. 3871-93.

24. R. Kolmorgen and H. Biermann: Int. J. Fatigue, 2012, vol. 37, pp. 86-91.

25. T. Leffers and R.K. Ray: Prog. Mater. Sci., 2009, vol. 54, pp. 351-96.

26. R.K. Ray: Acta Metall. Mater., 1995, vol. 43, pp. 3861-72.

27. G. Wassermann and J. Grewen: Texturen Metallisclzer Werkstoffe, Springer, Berlin, 1962.

28. P.C.J. Gallagher: Metall. Trans., 1970, vol. 1, pp. 2429-61.

29. R.M. Latanision and A.W. Ruff: Metall Trans., 1971, vol. 2, pp. 505-09.

30. R.E. Smallman and D. Green: Acta Metall., 1964, vol. 12, pp. 14554.

31. R. Saha and R.K. Ray: J. Mater. Sci., 2007, vol. 42, pp. 9548-52.

32. M.R. Barnett and J.J. Jonas: ISIJ Int., 1997, vol. 37, pp. 697-705.

33. T. Senuma, H. Yada, R. Shimizu, and J. Harase: Acta Metall. Mater., 1980, vol. 38, pp. 2673-81.

34. J.L. Raphanel and P. Van Houtte: Acta Metall., 1985, vol. 33, pp. 1481-88. 